\title{
METODOLOGIAS ATIVAS EM EAD NA VISÃO DOS EDUCADORES
}

\author{
SÃO PAULO/SP JULHO/2018 \\ Solimar Garcia －UNIP - solimargarcia10@gmail.com \\ Tipo: Investigação Científica (IC) \\ Natureza: Relatório Final de Pesquisa \\ Categoria: Métodos e Tecnologias \\ Setor Educacional: EDUCAÇÃO SUPERIOR
}

\begin{abstract}
RESUMO
A educação a distância em poucos anos terá mais alunos do que o ensino presencial. Mais do que um diploma universitário trata-se de inclusão social e acesso a ensino de qualidade, situação na qual todos os envolvidos têm se empenhado: academia, governos, empresas, professores, tutores e todo o corpo profissional envolvido. As metodologias ativas adequadas à EaD começam a tomar forma em algumas instituições. O objetivo dessa pesquisa foi ouvir professores e tutores sobre as metodologias ativas que facilitariam o aprendizado do estudante e sugestões para que a metodologia torne-se realidade, elevando a qualidade do ensino e dos cursos a distância. Este trabalho foi realizado por meio de pesquisa bibliográfica dos principais estudiosos de EaD, do Censo Abed 2016 e um estudo qualitativo de campo, com a distribuição de questionários pelas redes sociais e por e-mail a uma amostra disponível e conveniente à pesquisadora, forma por professores e tutores participantes de grupos específicos sobre esse tema, que resultou em 63 respostas analisadas. Os resultados mostram que os professores e tutores compreendem as metodologias ativas como mais adequadas aos cursos a distância, mas estão presos aos sistemas engessados oferecidos pelas universidades, nas quais a sua atuação pouco interfere no que o estudante aprende. Mostra-se ainda que a experiência das inteligências múltiplas de Gardner pode representar inovações para a EaD.
\end{abstract}

Palavras-chave: 1.Papel do tutor. 2. EaD. 3. Discussões em grupo. 4. Fóruns. 5. Ferramentas colaborativas. 6. Projetos em EaD.

AGRADECIMENTOS

AGRADEÇO À UNIVERSIDADE PAULISTA UNIP PELA BOLSA DE ESTUDO DE PÓSGRADUAÇÃO EM FORMAÇÃO EM EDUCAÇÃO A DISTÂNCIA. 


\section{INTRODUÇÃO}

Pesquisas apontam que os estudantes da EaD vão superar a quantidade dos presenciais em cinco anos e somavam 843 mil em 2016, um terço do total de universitários (G1, 2017). Os avanços e as aplicaçãos das Tecnologias Digitais da Informação e Comunicação (TDICs) e a atuação do professor e do tutor nos cursos a distância buscam criar formas para manter o estudante ativo nos ambientes virtuais de aprendizagem. O estudante a distância busca praticidade, economia de tempo por não se deslocar e comodidade por não ter um horário determinado. Estudar a distância não é facilidade na obtenção de diploma de curso superior e manter o estudante motivado e atuante no AVA é fundamental para que mantenha um aprendizado constante e de qualidade.

A atuação dos professores e tutores é fundamental na manutenção de seu interesse no AVA. As metodologias ativas e as TDICs têm sido abordadas apenas transpondo o ensino presencial para a educação a distância, com poucas aplicações específicas para a modalidade. O uso das ferramentas é tímido e são utilizadas para entrega de conteúdo, e o estudante utiliza outras plataformas, que não o AVA, para comunicação e estudo. As metodologias ativas, que comportam diversas formas de ensino para a modalidade presencial, como método caso, aprendizagem baseada em problemas, em projetos, em games e gamificação, sala de aula invertida, design thinking e peer instruction, entre outras (MATTAR, 2017), começam a ser abordadas na educação a distância e ainda é um campo de estudo novo para a área. As metodologias utilizadas para ensinar o estudante devem ser adaptadas para a educação a distância e primar pelo aumento da qualidade dos cursos, fonte de preocupações nos níveis governamental, institucional e pedagógico (TARCIA et al., 2016).

\section{Objetivos}

O objetivo desse artigo é avaliar as ferramentas das metodologias ativas e seu uso na educação a distância, do ponto de vista dos professores e tutores que atuam em EaD e apresentar sugestões para sua aplicação.

\section{FUNDAMENTAÇÃO TEÓRICA}

Segundo Bloom (1956), a cognição se dá pelas habilidades hierarquizadas, conforme o grau de complexidade de seu processamento. Nessa hierarquia, o conhecimento é o nível mais primário, passando pela compreensão, aplicação, análise, síntese e avaliação, o nível mais complexo. Pode-se dizer, que apesar da rápida evolução 
tecnológica e de seu uso para a $\mathrm{EaD}$, as tecnologias tem-se limitado a imitar a educação presencial, numa abordagem broadcast, que apropria-se da tecnologia para passar informações aos estudantes, sem nenhuma interação, ou da "virtualização da escola tradicional", uma junçao entre o broadcast e o estar junto virtual, com o uso da comunicação e da educação com base nas tecnologias digitais, como ensina Valente (2014).

Gardner (2000), ao estudar a forma como se compreende o mundo e a cognição, nos anos 1980, apresentou nove tipos de inteligência que são diferentes e complementares entre si: verbal ou linguística, lógico-matemática, musical, visual ou espacial, corporal ou cinestésica, interpessoal, intrapessoal, naturalista e existencialista; as duas últimas em suas obras mais recentes (GARDNER, 2007).

As atividades que desenvolvam e deem ênfase a cada uma das inteligências podem ser utilizados de muitas maneiras, em EaD, dados os recursos tecnológicos que podem ser apresentados nos AVAs.

Pela teoria de Glasser, as pessoas aprendem de formas diferentes em cada situação e ao adaptá-la para as metodologias utilizadas em educação pode-se observar a composição mostrada na figura 1.

Figura 1 - Adaptação da pirâmide da aprendizagem

\section{Como aprendemos}

Adaptado da pirâmide de aprendizagem de William Glasser

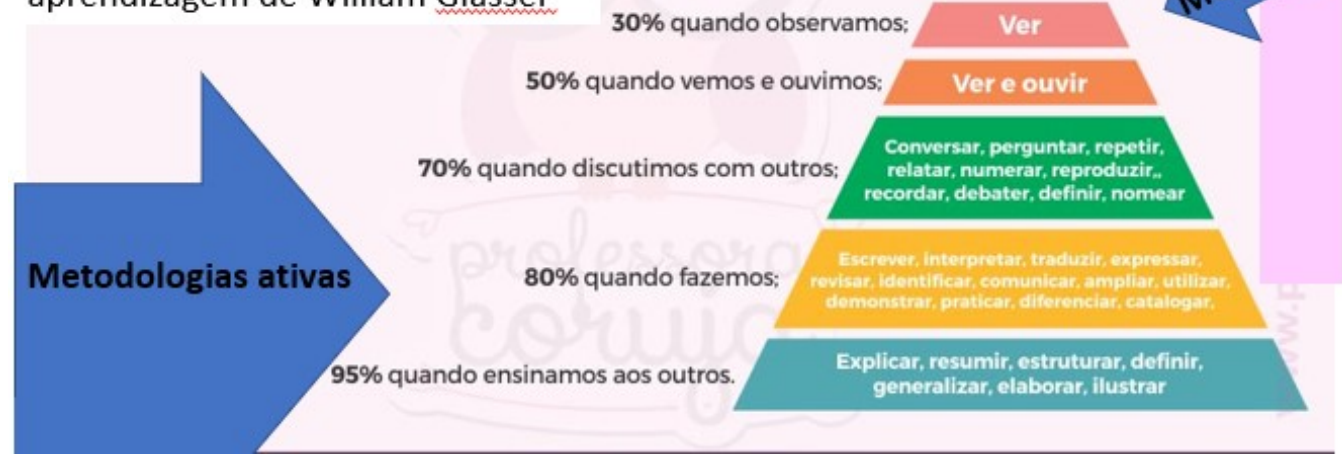

Aprendemos.

$10 \%$ quando lemos:

$20 \%$ quando ouvimos; Escutar Ver

.

.


As aulas expositivas não devem ser o modelo principal para as aulas, pois não facilita a construção do conhecimento e as TDICs têm possibilitado abordagens de aprendizagem ativa, conforme apontado por Fonseca e Mattar (2017, p. 185); Sta (2016); Mattar e Nesteriuk (2016); Pinto et al. (2013); Alvarez (2009); Berbel (2011); Gouvêa et al. (2016a, 2016b); Diesel (2017), Silva (2013): problematização (solução de problemas); metodologia com o Arco de Maguerez (solução de problemas em cinco etapas); resolução de problema (por meio de administração de problemas, por debates e método caso); sala de aula invertida (flipped classrom - primeiro, o estudante faz a lição de casa e depois participa da aula); aprendizagem baseada em projetos (multidisciplinares de diversas áreas e equipes variadas e até de locais diferentes); aprendizagem baseada em equipes (team-based learning - formação de todos os tipos de grupos); aprendizagem entre pares (peer instruction - atividades e avaliações entre os pares); aprender fazendo (hands on - mão na massa - simula a realidade de uma empresa e suas dificuldades); design thinking (processo para acelerar a inovação por meio de pensamento crítico, do qual a prototipagem faz parte do processo); dramatização (role playing - assumir outras personagens e cargos para vivenciar as dificuldades reais de uma empresa); estudo de caso, simulações e seminários (apresentações de pesquisas e casos reais, simulados como se fossem realidade); objetos virtuais de aprendizagem (OVAs - todo o tipo de mídia utilizada no processo de ensino e aprendizagem online vídeos, áudios, fóruns de discussão, ambientes simulados, entre outros); encontro presencial; ferramenta glossário (criado pelos estudantes).

Staa em palestra sobre metodologias ativas (2016) reforça a necessidade de colocar a produção de materiais nas mãos do estudante, seja na forma de textos, vídeos, animação, softwares, tweets, blogues e outros.

\section{Metodologias ativas em educação a distância}

Valente (2014) apresenta o uso das TDICs para substituir as atividades feitas pelo estudante no papel, por meio de ferramentas digitais, com a simulação e as narrativas digitais. O uso das narrativas, que não é novo, ganhou a possibilidade da combinação de mídias, como os smartphones e os laptops dotados de camera fotográfica, de vídeo, gravador de som e microfones, para a criação individual ou conjunta de narrativas digitais (ALMEIDA, VALENTE, 2012). Acrescente-se ainda os aplicativos em geral que manipulam imagens, textos e vídeos e a possibilidade do trabalho colaborativo entre estudantes, professores e outros envolvidos na produção do conhecimento, que sem a necessidade de serem especialistas em tecnologia, podem produzir muitos tipos de atividades e exercícios. Almeida e Valente (2012, p. 55) chamam a atenção para as muitas possibilidades de produção de narrativas digitais, em inglês, digital storytelling, 
como "histórias digitais, relatos digitais, narrativas interativas, narrativas multimídia ou multimidiáticas".

\section{PROCEDIMENTOS METODOLÓGICOS}

O trabalho foi realizado por meio de pesquisa bibliográfica sobre os temas pertinentes. Trata-se de um estudo de caso, que na abordagem de Yin (2010), apresenta uma investigação prática de um fenômeno atual e contemporâneo em seu contexto real. Optou-se por uma pesquisa de cunho qualitativa, com a análise de experiências de pessoas ou grupos advindas de práticas cotidianas ou profissionais (FLICK, 2009). Corroborando Yin (2010), buscou-se respostas para oferecer subsídios que contribuam com os conhecimentos da área. Foi realizado um levantamento com professores e tutores de cursos a distância para captar suas sugestões de melhoria para as atividades em EaD que possam contribuir com o aprendizado do estudante. A pesquisa foi aplicada a uma amostra conveniente e disponível à pesquisadora, totalizando 63 questionários de tutores/professores, membros de comunidades específicas em redes sociais. Os dados foram coletados entre os dias 03 e 23 de outubro de 2017, por meio de questionário online criado pela ferramenta GoogleDocs, distribuído pelas redes sociais e por email. Os dados coletados foram analisados e confrontados com os autores estudados, criandose as propostas apresentadas para o uso das metodologias ativas na EaD.

\section{RESULTADOS E DISCUSSÃO}

Na pesquisa realizada com os professores e tutores obteve-se na questão: você sabe o que são metodologias ativas em EaD? mais de $87 \%$ de conhecimento como resposta, mas chama a atenção cerca de $13 \%$ não conhecer o tema. Na sequência buscou-se informações sobre o que os professores e tutores consideram fundamental para o aprendizado do estudante, que resultou na tabela 1.

Tabela 1 - O que professores e tutores consideram fundamental para o aprendizado

\begin{tabular}{|c|c|}
\hline $65,1 \%$ 표 & Realizar-atividades colaborativas-(41) a \\
\hline $65,1 \%$ 표 & Participar-de-grupos'de-discussão-(41)a \\
\hline $58,7 \%$ 표 & Realizar-atividades-práticas-(37) $a$ \\
\hline $52,4 \%$ 묘 & Leitura-do material·(33) $\mathrm{a}$ \\
\hline $49,2 \%$ क् & Participar de-aulas em vídeos $\cdot$ com professor-e-colegas $\cdot(31)^{a}$ \\
\hline $46 \%$ क & Tirar·dúvidas·em·fóruns-(29)a \\
\hline $46 \%$ s & Realizar-atividades-em-equipe-(29)a \\
\hline $46 \%$ s & Assistir-aulas·em-vídeos-(29)a \\
\hline $22,2 \%$ x & 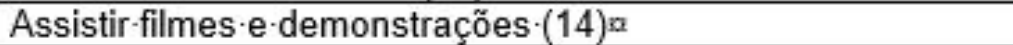 \\
\hline
\end{tabular}

Fonte: a autora (2018). 
O terceiro questionamento era uma pergunta aberta, na qual o professor/tutor poderia se manifestar livremente e apresentar sugestões de atividades para facilitar o aprendizado dos estudantes em EaD. As respostas foram diversas e divididas por temas para esta análise: atividades (6); atividades em grupo (16); atividades presenciais (3); atividades práticas (4); interatividade (8); fóruns (5); avaliação e feedback (5); tecnologia (4); videoaulas (3); análise crítica (3); nada a declarar (3) e tutoria ativa (1).

Pode-se observar que o maior número de sugestões gira em torno da realização das atividades, com prevalência para as atividades em grupo, das quais pode-se destacar, entre outras: "atividades colaborativas; centradas em exemplos; que priorizem a interação e com projetos". Entre as sugestões de atividades presenciais pode-se destacar: "estímulo à visita a museus e websites; aprender a pesquisar, investigar; visitas a empresas, instituições e entidades de classe; maior participação do tutor do polo". Para atividades práticas resultaram: "atividades que aliam a teoria às práticas pessoais e profissionais do aluno; conceitos vinculados à prática; consultoria acadêmica para comunidade; assuntos do dia a dia adaptados ao curso; casos práticos de mercado". As sugestões dos professores e tutores corrobora as metodologias ativas propostas pelas narrativas digitais, que atualiza o ato de contar histórias, com recursos audiovisuais e tecnologógicos, por meio das diversas práticas de digital storytelling na educação (VALENTE, 2014) e Yuksel et al. (2011), que apresentam um quadro geral sobre os usos educacionais das narrativas.

Pela prática profissional em EaD, observa-se que há grande dificuldade na realização de trabalhos em grupo, no entanto, há um impulsionador para isso, que a realização de atividades voltadas para a prática profissional presencialmente nos polos poderia ser uma condição importante. As indicações de atividades presenciais, por meio da proposição de Bloom, demonstram que a execução dos projetos institucionais possam estimular as atividades de pesquisa e produções individuais e coletivas de forma mais contundente. Outra possibilidade para a realização de trabalhos em equipe poderia ser o foco do curso estar na aprendizagem baseada em equipes, seguindo Staa (2016), que sugere o uso das discussões como foco de aulas, seja em grupos grandes, pequenos, em trios, em duplas, discussões remotas e do tipo brainstorming, e Rosa Júnior (2015), que apresenta vantagens como aumentar o conhecimento entre os participantes, com melhora do relacionamento interpessoal, análise crítica e outros.

Por estar inserido no universo da EaD pode-se identificar que os encontros não precisam ser físicos, mas realizados virtualmente pelas tecnologias disponíveis nos AVAs ou em tantas ferramentas gratuitas e livres na internet, como o Skype e o Hangout. O que leva ao outro ponto com muitas sugestões que se agruparam num tema 
chamado interatividade, que indicam a necessidade de mais contato com o professor, seja por webconferências, chats, fóruns, aulas gravadas e ao vivo. As sugestões versaram na necessidade de aumentar o contato com o estudante. O estar presente virtual, tão bem compreendido pela comunicação e pela propaganda no marketing digital, é um ponto de atenção para a EaD. As indicações mostram a necessidade de estar mais próximo ao estudante, seja por contato escrito, síncrono e com visualização entre os envolvidos, o que leva aos outros dois pontos de sugestões: fóruns e videoaulas, bastante lembrados pelos professores e tutores.

Pelas respostas obtidas observa-se que, apesar dos esforços pela autonomia e responsabilidade do estudante na construção de seu conhecimento, há ainda uma dependência grande do estudante em relação ao professor expositivo. Os estudantes de $\mathrm{EaD}$, apesar de serem mais independentes e autodidatas do que os presenciais, não demonstram familiaridade com metodologias que os coloquem como responsáveis pelo próprio aprendizado, corroborando professores e tutores, que gostariam de ter mais atitudes observadas em aulas expositivas. Para a realização dos fóruns apareceram sugestões, como a utilização de vídeos de apresentação, troca de mensagens por vídeos, discussão de temas práticos e atuais. Sobre videoaulas, foram sugeridas além das próprias, que sejam realizadas on-line, além de expressarem a necessidade de ampliar a oferta de vídeos gravados sobre teoria e prática dos temas estudados.

Apareceram respostas que tratam de funções como tutorias ativas e situações que possam aumentar a capacidade crítica do estudante, por meio de reflexão, atividades de pesquisa e debate de temas atuais, com propostas de melhorias e alternativas para problemas reais. Alguns pontos sugeridos tratando de avaliação e feedback mostram a necessidade de melhoria quanto aos feedbacks fornecidos para acompanhamento e avaliação do estudante. Outros ainda sugerem novas formas de utilização e aproveitamento da tecnologia, com entrega de atividades por meio de vídeo e webconferências.

\section{CONSIDERAÇÕES FINAIS}

As indicações mostram que os professores e tutores compreendem a necessidade da ampliação das metodologias ativas, mas esbarram no engessamento observado nas estruturas das instituições e seus cursos a distância. Pode-se entender como um contrassenso, empresas que dispõem de tecnologia avançada para realizar sua atividade-fim ter dificuldade em alterar atividades, formatos de entrega, formas de comunicação, seja entre estudantes, professores, coordenadores e instâncias administrativas. 
A EaD é um ambiente propício para as experimentações, com diversas aplicações e formatos de atividades, a utilização de imagens, sons, textos, filmes e outros, corroborando Gardner (2000; 2007), e as abordagens das inteligências múltiplas: linguística, lógico-matemática, musical, visual ou espacial, cinestésica, interpessoal, intrapessoal, naturalista e existencialista As sugestões dos professores e tutores corroboram Longo (2016) e apontam para o hibridismo em todos os níveis educacionais, sobretudo no ensino superior, o que deve facilitar a utilização de metodologias ativas, corrobora o resultado dessa pesquisa.

Os vídeos, tão populares atualmente, podem ser melhor aproveitados no ambiente educacional, seja para aulas, webconferências, comunicação e feedback de atividades. Há muito potencial a ser explorado, uma vez que ainda são utilizados na maioria dos casos como material instrucionista, na forma de videoaula. A utilização de metodologias ativas em EaD ainda é uma promessa das universidades, mas trata-se de uma mudança na concepção de educação das universidades que não depende apenas de atitudes isoladas de professores e tutores, mas de novas propostas institucionais.

Embora não se pretendesse estudar nenhuma instituição em particular, a falta de qualificação dos professores e tutores é uma das limitações desse estudo, bem como a quantidade de respostas analisadas, que não permite uma extrapolação genérica dos resultados. Como sequência, sugere-se o levantamento das mesmas informações na visão dos polos, designers instrucionais e profissionais de tecnologia. A visão do aluno já foi apresentada em artigo que está em processo de revisão em um periódico.

\section{REFERENNCIAS}

ABED. Associação Brasileira de Educação a Distância. Censo EAD Brasil 2016. Relatório Analítico de Aprendizagem a Distância no Brasil. Censo EaDBR Abed 2016.

ALMEIDA, M. E. B.; VALENTE, J. A. Tecnologias Digitais, Linguagens e Currículo: investigação, construção de conhecimento e produção de narrativas. São Paulo: Coleção Agrinho, 2012.

ALVAREZ, Ana Graziela. Objeto virtual de aprendizagem simulada em Enfermagem para a avaliação da dor aguda em adultos. 2009. 198 f. Dissertação (Mestrado em Enfermagem)-Universidade Federal de Santa Catarina, Florianópolis, 2009.

BERBEL, Neusi. As metodologias ativas e a promoção da autonomia dos estudantes. Semina: Ciências Sociais e Humanas, Londrina, v. 32, n. 1, p. 25-40, jan./jun. 2011. 
BLOOM, B. S. et al. Taxonomy of educational objectives. New York: David Mckay, 1956. 262 p. (v. 1)

DIESEL, Aline; BALDEZ, Alda Leila Santos; MARTINS, Silvana Neumann. Os princípios das metodologias ativas de ensino: uma abordagem teórica. Revista Thema. 2017, Volume 14, № 1, p. $268-288$.

FLICK, Uwe. Qualidade na pesquisa qualitativa. Tradução Roberto Cataldo Costa. Porto Alegre: Artmed, 2009.

FONSECA, Sandra Medeiros; MATTAR, João Augusto Neto. Metodologias ativas aplicadas à educação a distância: revisão de literature. Revista EDaPECI São Cristóvão (SE) v.17. n. 2, p. 185-197 mai./ago. 2017.

G1. Após alta de $20 \%$ nos estudantes de cursos à distância, ministro quer travar uso da EAD na área da saúde. Portal G1. 31.08.2017. Disponível em: https://g1.globo.com/edu cacao/noticia/apos-alta-de-20-nos-estudantes-de-cursos-a-distancia-ministro-quer-travaruso-da-ead-na-area-da-saude.ghtml. Acesso em: 15 out. 2017.

GARDNER, Howard. Inteligências múltiplas, a teoria na prática. Porto Alegre: 2000.

GARDNER, Howard. Cinco mentes para o futuro. Trad. Cataldo Costa. São Paulo: Artmed, 2007.

GLASSER, W. Control theory in the classroom. New York: Perennial Library/Harper \& Row Publishers, v. vi 144 pp., 1986.

GOUVÊA, Eduardo Penna et al. Metodologia ativa: estudo de caso sobre o recurso encontro presencial em curso de educação a distância. Revista Acadêmica da Faculdade Fernão Dias, ano 3, n. 9, p.1-14, ago. 2016a.

GOUVÊA, Eduardo Penna et al. Metodologia ativa: um estudo de caso sobre a ferramenta glossário em ambientes virtuais de educação a distância. Educação, Gestão e Sociedade: revista da Faculdade Eça de Queirós, ano 06, n. 22, p.1-13, 22 jun. 2016b.

LONGO, Carlos. A regulação da educação a distância e a qualidade do setor: dados de opinião. In Censo EADBr 2016. Associação Brasileiras de Educação a Distância, Abed. 2016. 
MATTAR, J. Metodologias ativas para a educação presencial, blended e a distância. São Paulo: Artesanato Educacional, 2017.

MATTAR, João; NESTERIUK, Sérgio. Estratégias do design de games que podem ser incorporadas à educação a distância. Ried - Revista Iberoamericana de Educación a Distancia, v. 19, n. 2, p. 91-106, mar. 2016.

PINTO, Antonio Sávio da Silva et al. O Laboratório de Metodologias Inovadoras e sua pesquisa sobre o uso de metodologias ativas pelos cursos de licenciatura do UNISAL, Lorena: estendendo o conhecimento para além da sala de aula. Revista Ciências da Educação, ano XV, v. 2, n. 29, p.67-79, dez. 2013.

ROSA JUNIOR, Luiz Carlos. Metodologias ativas de aprendizagem para a educação a distância: uma análise didática para dinamizar sua aplicabilidade. 2015. $100 \mathrm{f}$. Dissertação (Mestrado em Tecnologias da Inteligência e Design Digital)—Pontifícia Universidade Católica de São Paulo, São Paulo, 2015.

SILVA, Salete. Aprendizagem ativa. Ensino Superior. 15.07.2013. Disponível em: http://www.revistaeducacao.com.br/aprendizagem-ativa/, acesso em: 27 out. 2017.

STAA, Betina von. Palestra sobre Metodologias Ativas. Disponível em: http://abed.org.br/dnead2016/DNEAD_2016_Betina_von_Staa.pdf, acesso em: 20 nov. 2017.

TARCIA, Rita Maria Lino; ARSENOVICZ, Karen Diana Macedo; FREITAS, Adriana Domingues; MACHADO, Cristiane. Os significados da qualidade na EAD. In Censo EADBr. Associação Brasileira de Educação a Distância, Abed. 2017.

VALENTE, José Armando. A comunicação e a educação baseada no uso das tecnologias de digitais de informação e comunicação. Revista Unifeso - Humanas e Sociais, v. 1, n. 1, p.141-166, 2014.

YIN, R. K. Estudo de caso: planejamento e métodos. 4. ed. Porto Alegre: Bookman, 2010.

YUKSEL, P., ROBIN, B.; MCNEIL, S. Educational uses of digital storytelling all around the world. In: KOEHLER, M.; MISHRA, P. (eds.), Proceedings of Society for Information Technology \& Teacher Education International Conference 2011. 2011, p. 1264-1271. Chesapeake, VA: AACE. 